\title{
Sham Feeding? Same Feeding?
}

\author{
Hungdai Kim \\ Department of Surgery, Gastrointestinal Cancer Center, Kangbuk Samsung Medical Center, Seoul, Korea
}

\section{See Article on Page 248-251}

Most patients who undergo abdominal surgery might experience a varying degree of postoperative paralytic ileus (PPI). Although most PPI is resolved spontaneously, $20-30 \%$ of PPI patients suffer from prolonged PPI. Prolonged PPI may not only delay a patients' recovery but also increase medical costs. The pathogenesis of PPI is multifactorial. Several factors related to PPI are sympathetic stimulation; release of gut hormones, neurotransmitters, and other mediators; anesthesia; inflammatory reaction; and the effects of analgesics [1]. For many years, various methods have been attempted to eliminate PPI. However the results have been neither satisfactory nor absolute.

Recently, the numbers of laparoscopic colorectal surgery have increased steeply. Laparoscopic procedures yield less tissue damage, and that difference may decrease the duration of PPI. According previous similar studies, patients who underwent laparoscopic colorectal surgery had a shorter PPI period than those who underwent open surgery [2-4]. Nevertheless, still some patients have prolonged PPI.

The authors conducted a two-arm study of 132 patients with colorectal cancer who underwent a laparoscopic colorectal resection to investigate the effect of sham feeding on PPI's duration. They used gum-chewing to activate the cephalic phase of vagal stimulation. Results of their study showed less than a 1-day difference in hospital stays, but that difference was statistically significant [5]. A meta-analysis of gum-chewing therapy following open gastrointestinal surgery demonstrated that it had been beneficial in reducing the period of postoperative ileus, but no statistically significant reduction in the length of hospital stay was demonstrated. These outcomes are not significant for laparoscopic gastrointestinal surgery [6]; thus, if the authors' conclusions are to be

Correspondence to: Hungdai Kim, M.D.

Department of Surgery, Kangbuk Samsung Medical Center, 29 Saemunan-ro, Jongno-gu, Seoul 110-746, Korea

Tel: +82-2-2001-8335, Fax: +82-2-2001-2131

Email: hungdai.kim@samsung.com

(C) 2013 The Korean Society of Coloproctology

This is an open-access article distributed under the terms of the Creative Commons Attribution NonCommercial License (http://creativecommons.org/licenses/by-nc/3.0) which permits unrestricted noncommercial use, distribution, and reproduction in any medium, provided the original work is properly cited. accepted, more obvious evidence is needed.

In PPI, return of colonic motility is a hindmost concern; it takes 48 to 72 hours. Sham feeding enhances gastric emptying and increases rectosigmoid pressure activity. However, the influence of gum chewing on colonic motility is not clear. Alvimopan, a peripherally-acting $\mu$-opioid receptor antagonist, was recently approved for the reduction of PPI after open or laparoscopic colectomy [7]. I believe that various multimodality treatments, including sham feeding, that might reduce risk factors for PPI would be best practices in the current clinical setting. In comparison with those in the past, recent durations of PPI have been markedly reduced, but room for improvement still exists.

\section{REFERENCES}

1. Baig MK, Wexner SD. Postoperative ileus: a review. Dis Colon Rectum 2004;47:516-26.

2. Han KS, Choi GS, Park JS, Kim HJ, Park SY, Jun SH. Short-term outcomes of a laparoscopic left hemicolectomy for descending colon cancer: retrospective comparison with an open left hemicolectomy. J Korean Soc Coloproctol 2010;26:347-53.

3. Koh FH, Tan KK, Tsang CB, Koh DC. Laparoscopic versus an open colectomy in an emergency setting: a case-controlled study. Ann Coloproctol 2013;29:12-6.

4. Mamidanna R, Faiz O. Laparoscopic colectomy is safe and leads to a significantly shorter hospital stay for octogenarians. Surg Endosc 2011;25:983-4.

5. Hwang DY, Kim HY, Kim JH, Lee IG, Kim JK, Oh ST, et al. Effect of gum chewing on the recovery of laparoscopic colorectal cancer surgery. Ann Coloproctol 2013;29:248-51.

6. Fitzgerald JE, Ahmed I. Systematic review and meta-analysis of chewing-gum therapy in the reduction of postoperative paralytic ileus following gastrointestinal surgery. World J Surg 2009;33: 2557-66.

7. Obokhare ID, Champagne B, Stein SL, Krpata D, Delaney CP. The effect of alvimopan on recovery after laparoscopic segmental colectomy. Dis Colon Rectum 2011;54:743-6. 